Florida International University FIU Digital Commons

4-10-2001

\title{
Personality, motivation, and training performance of firefighter candidates
}

Gregory David Anderson

Florida International University

DOI: $10.25148 /$ etd.FI14030205

Follow this and additional works at: https://digitalcommons.fiu.edu/etd

Part of the Psychiatry and Psychology Commons

\section{Recommended Citation}

Anderson, Gregory David, "Personality, motivation, and training performance of firefighter candidates" (2001). FIU Electronic Theses and Dissertations. 1053.

https://digitalcommons.fiu.edu/etd/1053 


\section{FLORIDA INTERNATIONAL UNIVERSITY}

Miami, Florida

PERSONALITY, MOTIVATION, AND TRAINING PERFORMANCE OF FIREFIGHTER CANDIDATES

A thesis submitted in partial fulfillment of the requirements for the degree of MASTER OF SCIENCE in PSYCHOLOGY by

Gregory David Anderson 


\section{To: Dean ArthurW. Herriott \\ College of Arts and Sciences}

This thesis, written by Gregory David Anderson, and entitled Personality, Motivation, and Training Performance of Firefighter Candidates, having been approved in respect to style and intellectual content, is referred to you for judgment.

We have read this thesis and recommend that it be approved.

Heidi M. Von Harscher

Michael R. Markham

Chockalingam Viswesvaran, Major Professor

Date of Defense: April 10, 2001

The thesis of Gregory David Anderson is approved.

Dean Arthur W. Herriott

College of Arts and Sciences

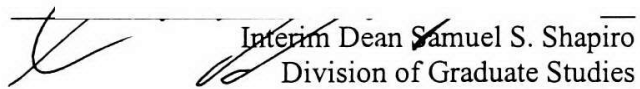

Florida International University, 2001 
(C) Copyright 2001 by Gregory David Anderson

All rights reserved. 
I wish to thank the members of my committee, Dr. Chockalingam "Vish" Viswesvaran, Dr. Michael R. Markham, and Dr. Heidi M. Von Harscher. It's been a long road, and I truly appreciate the knowledge that you've imparted to me along the way. Of course, the road would have been much longer if not for the love, support, and motivation that I received from Andrea, my wife and best friend. 
ABSTRACT OF THE THESIS

PERSONALITY, MOTIVATION, AND TRAINING PERFORMANCE OF FIREFIGHTER CANDIDATES

\author{
by \\ Gregory David Anderson \\ Florida International University, 2001 \\ Miami, Florida \\ Professor Chockalingam Viswesvaran, Major Professor
}

The purpose of this research was to investigate the validity of personality for predicting training and job performance in a sample of firefighters, and to determine if motivation could act as a moderator in the personality-performance relationship.

Personality and motivation inventories were administered to 109 firefighter candidates from three academy classes. At the termination of each academy, all candidates were assessed on their overall performance.

Correlation coefficients were used to measure the relationship between personality inventory scales, motivation inventory scales, and the overall training performance measures. A multiple regression procedure was used to investigate the relationship between personality, motivation, and performance to determine if motivation had a moderation effect on performance.

None of the correlations were statistically significant at the 0.05 level. The two highest were sociability $(r=0.13, p=.189)$ and school success $(r=0.11, p .262)$. With 
regard to the multiple regression, for the sample of low thrill-seeker subjects, the $r^{2}$ for the motivation and thrill-seeking variables was $.0578(\mathrm{~F}=.7665)$. Adding the combined variable (thrill-seeking $\mathrm{x}$ motivation) into the equation provided a $\Delta \mathrm{r}^{2}$ of $.0217(\Delta \mathrm{F}=$ .5652). For the sample of high thrill-seeker subjects, the $\mathrm{r}^{2}$ for the motivation and thrillseeking variables was $.0513(\mathrm{~F}=1.6226)$. Adding the product variable (thrill-seeking $\mathrm{x}$ motivation) into the equation provided a $\Delta \mathrm{r}^{2}$ of $.0004(\Delta \mathrm{F}=.0215)$. Although motivation seemed to moderate personality when predicting training performance to a greater extent in the low thrill-seeker sample than it did in the high thrill-seeker sample, the results were not significant.

Since the personality and motivation inventories had been previously shown to be related to performance, a possible explanation for the current results is that the measure used in the study was a poor indicator of performance. Future studies should use performance measures specifically designed to measure the objectives of the academy, which should stem from the essential functions of the job as determined by a job analysis. 


\section{TABLE OF CONTENTS}

CHAPTER

PAGE

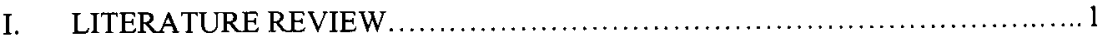

Personality and Job Performance ........................................... 3

Personality and Hazardous Job Performance $\ldots \ldots \ldots \ldots \ldots \ldots \ldots \ldots \ldots \ldots \ldots \ldots \ldots, 8$

Personality and Training Performance..................................... 10

The Role of Motivation on the Personality - Performance Link................ 11

Summary of Hypotheses . ............................................... 14

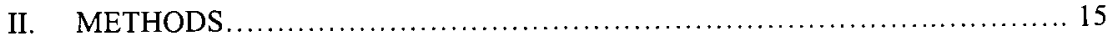

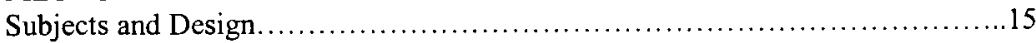

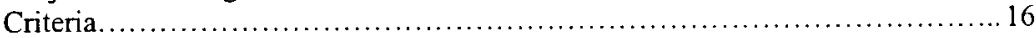

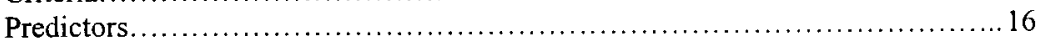

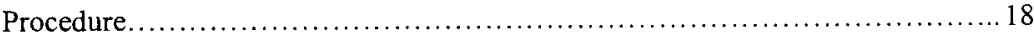

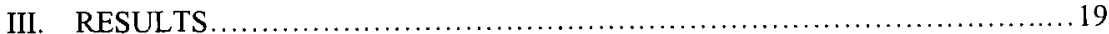

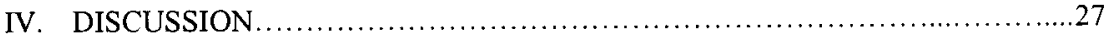

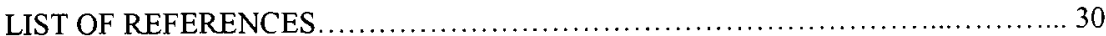

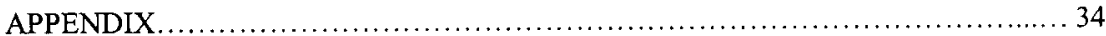




\section{LIST OF TABLES}

TABLE

PAGE

1. Summary of the demographic characteristics of sample ....................... 19

2. Intercorrelations among the seven primary scales of HPI....................... 20

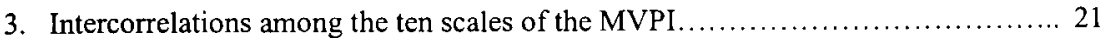

4. Intercorrelations among the seven criterion measures $\ldots \ldots \ldots \ldots \ldots \ldots \ldots \ldots \ldots \ldots \ldots \ldots \ldots \ldots \ldots \ldots$

5. Correlations between the seven HPI scales and the performance criteria........... 22

6. Correlations between the ten MVPI scales and the performance criteria............ 23

7. Results of moderation of motivation when predicting training performance ......... 24

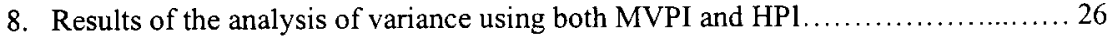




\section{LITERATURE REVIEW}

For over fifty years researchers and professionals in the applied setting have used personality tests in an effort to predict job performance. Personality has been used to predict numerous criteria such as automobile accidents (Azen, Snibbe, \& Montgomery, 1973; Marsh, I962), job tenure (Saxe \& Reiser, 1976), police academy performance and attrition (Eisenberg, 1981 as cited in Bartol, 1991; Hargrave \& Berner, 1984), supervisor ratings of job performance (Gottlieb \& Baker, 1974), promotions, and job problems (Hiatt \& Hargrave, 1988), among other constructs.

Better identification of the applicants most likely be top performers, and identification of the applicants that are less likely to succeed (as suggested by Burbeck \& Furnham, 1985), will benefit both the organization and the individual. Some researchers question the validity of personality measures as screening tools for jobs (Reilly \& Warech, 1993), yet Hogan, Hogan and Roberts (1996) argue that well-constructed personality inventories predict occupational outcomes, produce scores that are stable over time, do not discriminate against any ethnic or national group, and allow disabled persons to demonstrate their qualifications without discrimination. Although there is impressive validity evidence of a relationship between personality and job performance, the validity of personality variables for predicting training and job performance of firefighters is limited. One purpose of this research is to investigate the validity of personality for predicting training performance in a sample of firefighters. 
Additionally, research has suggested that job performance is a function of motivation and ability. Campell (1990) provides the following formula: Job Performance $=f[$ Declarative Knowledge (facts, principles, goals, and self knowledge) $\boldsymbol{x}$ Procedural Knowledge and Skill (cognitive skill, psychomotor skill, physical skill, self-management skill, and interpersonal skill) $\boldsymbol{x}$ Motivation (choice to perform, level of effort, and persistence of effort)]. He points out that if an individual does not have knowledge of the goals of a job or the facts required to perform the job, performance will undoubtedly suffer. Similarly, if one does have the knowledge of that which is needed to be done, but does not have the ability to accomplish the tasks, performance will suffer. Lastly, if a person has both the knowledge and ability required for a job, but chooses to put forth little or no effort, performance will suffer. Empirical research investigating this multiplicative function of ability and motivation has not distinguished between motivation and personality. Another objective of this study, therefore, is to determine whether motivation is equally as predictive of job performance as personality, which will be discussed below.

The organization of this thesis is as follows: First, meta-analyses summarizing the relationship of personality and job performance will be reviewed. I emphasize the literature investigating the link between personality and job performance in hazardous jobs as well as in the role of personality in predicting training performance in this section. After summarizing the shortcomings in the existing literature, I present my hypotheses regarding the validity of personality for predicting training and job performance in hazardous jobs. I then discuss the link between personality, motivation and performance (both training and job performance). After summarizing my 
hypotheses, I present the methods (database, procedures, measures used, and analyses), results, and discussion (summary of results, implications for practice and theory), limitations, and future directions.

\section{Personality \& Job Performance}

Studies that have investigated the relationship between personality and job performance have proposed about as many different criteria as there have been studies. Those studies that have similar criteria, have similarly broad criteria. Early studies were unsuccessful at relating MMPI scores to job performance. However, in recent years, a number of meta-analyses have examined the relationship between job performance and personality (Anderson \& Viswesvaran, 1998; Mount, Barrick, \& Stewart, 1998; Barrick \& Mount, 1991; Tett, Jackson, \& Rothstein, 1991). These studies suggest that such a relationship exists. For each of these meta-analyses, the scales of the inventories were classified into the five personality factors as described by Costa and McCrae (1985). These five factors are described as Agreeableness- the degree to which one is cooperative, good natured, warm, trusting and agreeable versus cold, disagreeable, and antagonistic; Conscientiousness- the degree to which one is hardworking, organized, selfdisciplined, dependable, and persevering versus lazy, disorganized, and unreliable; Emotional Stability (Neuroticism reverse scored)- the degree to which one is calm, selfconfident, and cool versus insecure, impulsive, hostile, anxious, depressed, and emotional; Extraversion- the degree to which one is gregarious, assertive, excitementseeking, and sociable, versus reserved, timid, and quiet; and Openness to Experience- 
the degree to which one is creative, curious, and cultured, versus practical and narrowminded.

In a meta-analysis of 162 samples obtained from 117 non-military studies, Barrick and Mount (1991) hypothesized that Conscientiousness and Emotional Stability would predict job performance criteria across all jobs. They also hypothesized that Extraversion and Agreeableness would be valid predictors of jobs in management and sales, because these professions would likely require one to interact and cooperate with others. Since Openness to Experience describes one's curiosity and broadmindedness, they also posited that this dimension would predict training proficiency. Their first hypothesis was partially supported by a mean estimated true correlation between Conscientiousness and Performance (across all jobs) of .22, whereas Emotional Stability, contrary to their hypothesis, had a mean estimated true correlation of only .08. Their second hypothesis also was only partially supported, because Extraversion surfaced as predictive for managers (.18) and sales representatives (.15), but Agreeableness only had an estimated true correlation of .10 for managers, and .00 for sales. Of particular interest for the present study, their hypothesis that Openness to Experience would be predictive of training proficiency was supported with an estimated true correlation of 25 .

Additionally, Extraversion and Conscientiousness also were found to be predictive of training proficiency ( .26 and .23 respectively). Consistent with these results, my first hypothesis is that Extraversion, Openness to Experience, and Conscientiousness will predict overall training performance. The specific criteria and predictors used to measure this will be discussed in a later section of this paper. 
In a later meta-analytic study, Mount et al. (1998) investigated the extent to which the Five-Factor Model of personality was related to job performance in occupations that involved interpersonal interaction. They used eleven studies in the meta-analysis, with a criterion for inclusion that interpersonal interaction had to be a critical component of the job. The performance criteria used was supervisor ratings. They found the following true score correlations with job performance (accounting for unreliability in the predictor and criterion, and range restriction): Conscientiousness (.26), Agreeableness (.21), Emotional Stability (.18), Openness to Experience (.17), and Extraversion (.14). Nearly every activity that takes place at the fire academy involves interpersonal interaction, and even those activities (such as jogging) that are individual in nature are performed with the rest of the class, and the performance (or lack thereof) of one candidate can affect the whole group. Because the nature of the Fire Academy is one in which the cadets must work together in teams, the hypothesis that Conscientiousness will predict overall training performance is further justified.

Bringing the European perspective into view, Salgado (1997) conducted a metaanalysis of 36 non-military samples from European countries with a combined $\mathrm{N}$ of $2,722-3,877$, depending on the construct. Similar to Barrick and Mount, he hypothesized that Conscientiousness and Emotional Stability would be predictive across all jobs and criteria; that Extraversion and Agreeableness would be valid predictors for jobs where interpersonal elements were present (i.e. Managers and Police); and that Openness to Experience would be a valid predictor for training criteria. Like Barrick and Mount's (1991) study, he found that Conscientiousness was the most predictive of the Big Five and that it could be generalized across all jobs and criteria with an estimated 
true validity of .15 , hence supporting his first hypothesis. Contrary to Barrick and Mount (1991), he also found Emotional Stability to be predictive of job performance across all jobs and criteria with an estimated true validity of .13. In partial support of his second hypothesis, he found that the validity for Extraversion did generalize for police and managers, while Agreeableness was found to generalize for managers and skilled labor. Extraversion was found to be most predictive of Sales (-.17), Police (.13), and Skilled Labor (.12); whereas Agreeableness was most predictive of Police (.09) and Professionals (.09). Finally, consistent with both his hypothesis and the Barrick and Mount study, he found Openness to Experience to be a valid predictor for training proficiency (.17).

Another meta-analysis of the personality-performance relationship worthy of mention is that of Tett, Jackson, and Rothstein (1991). What differentiates this metaanalysis from the aforementioned two studies is that their analysis evaluated the difference in the validities between studies that used exploratory methods versus studies that used confirmatory methods. The Principles for the Validation and Use of Personnel Selection Procedures (1987) pointed out that, "a predictor is more likely to show validity if there is a good reason to suppose that a relationship exists between a predictor chosen and the behavior it is designed to predict (p. 11)." Their analysis included only published field studies of the direct relationship between self-report personality measures and nonself-report job performance criteria. The included studies reported empirical results and reported zero-order correlations, $t$ 's, and $F \mathrm{~s}$ based on two groups; or the means and standard deviations of extreme groups. Ultimately, they ended up with 86 studies ( 97 independent samples) with a combined $\mathrm{N}$ of 13,521 . The study produced an overall 
corrected estimate of the correlation between personality and job performance of 24 . More specifically, for the confirmatory studies, the combined sample-weighted mean correlation was .198 , whereas for the exploratory studies it was .081 . This supported their hypothesis that studies that do not make a conceptual link between personality and performance (i.e. exploratory studies) may underestimate the value of personality in the prediction of job performance. For the confirmatory studies, they found the order of sample-weighted mean validities to be: Agreeableness (.22), Openness to Experience (.184), Neuroticism (-.15), Conscientiousness (.121), and Extraversion (.104).

The relationship between personality and job performance in more recent literature was investigated in the meta-analysis conducted by Anderson and Viswesvaran (1998). Due to recent improvements in psychological measurement in recent years, and in an effort to avoid using any studies that may have been used in previous meta-analyses (hence using an entirely new database), their study included only those studies published after August 1992. Their meta-analysis consisted of 19 studies with a combined $\mathrm{N}$ of 3,369 to 6,817 , depending on the construct. They hypothesized that Conscientiousness and Emotional Stability would be valid predictors across all jobs. This was supported because Conscientiousness surfaced as the most predictive dimension with a corrected mean validity of .18 , followed by Emotional Stability with a corrected mean validity of .16.

In any event, the applicability of these meta-analytic results for hazardous job performance is an open empirical question. The following section will review some of extant literature that has investigated this relationship. 


\section{Personality \& Hazardous Job Performance}

Outside of the academic setting, the most common application of personality tests as a job performance predictor has been in the field of law enforcement. Where some studies have indicated that psychological measures can be used to predict the behavior of police officers (Butcher, 1979; Hargrave \& Berner, 1984; Hogan \& Kurtines, 1975; Spielberger, 1979), and that psychological screening can help identify applicants who have trouble coping with the physical and emotional stress of the job that could escalate incidents into life-threatening situations (Shusman, Inwald, \& Knatz, 1987).

Studies have shown that, in the law enforcement arena, officers who lack impulse control tend to withdraw (Baehr, Furcon, \& Froemel, 1968; as cited in Leitner \& Sedlacek, 1976); are perfectionist or rigid (Reiser \& Geiger, 1984); tend to disregard rules; and are suspicious of others (Lawrence, 1984). In fact, courts have ruled that preemployment psychological screening is a responsibility of the law enforcement agencies when it contributes to increased protection of citizens and officers (Conte v. Horcher, 1977; McKenna v. Fargo, 1978; Bonsignore v. City of New York ,1981).

Some studies have examined how job performance is predicted by a clinicians' assessment of overall test profiles (Hargrave \& Berner, 1984; Hargrave, 1985), while others have looked at the prediction of job performance by test and interview data combined (Hiatt \& Hargrave, 1988). The more predictors that are found to actually predict a unique part of the job performance variance, the better the selection methods will become.

An important part of such prediction, however, is the use of meaningful performance criteria. Defining and evaluating the performance construct is an important 
part using predictive assessments to forecast performance. Some researchers have used performance data that did not use ratings, such as tardiness, absences, turnover, disciplinary actions, assignment to restricted duty, negative or positive reports, job retention or termination, attitude problems, anxiety, mood, anger, anti-social characteristics, ability to accept criticism, interpersonal effectiveness, and intellectual characteristics (Inwald \& Shusman, 1984; Hargrave \& Berner, 1984; Roe \& Roe, 1982; Shusman et al., 1987; Cortina et al., 1992). One of the most common measures of performance; however, has been the use of either supervisor or peer ratings (Cortina et al., 1992; Shusman et al., 1987; Hargrave \& Berner, 1984; Inwald \& Shusman, 1984; Roe \& Roe, 1982).

Studies that have used psychological tests to predict performance and ratings of psychological suitability for cadets in law enforcement academies have shown some consistencies (Hargrave, 1985; Inwald \& Shusman, 1984). In a study of 314 police recruits, Cortina et al. (1992), used six (6) criterion measures: probation ratings, peer evaluation ratings, counseling cards, supervisory ratings, grade point average, and turnover. They found that the supervisory ratings were better predicted (by the Inwald Personality Inventory) than were peer ratings. More specifically, neuroticism had the highest correlation with supervisory ratings (-.23), followed by agreeableness (-.19), extraversion $(-.16)$, openness to experience $(-.15)$, and conscientiousness $(-.14)$. The order of prediction for the peer ratings was neuroticism (-.22), agreeableness and conscientiousness $(-.17)$, extraversion $(-.12)$, and openness to experience $(-.04)$. Since the majority of studies included in the aforementioned meta-analyses used supervisor ratings as the performance criteria, the same criteria were used for this study. 


\section{Personality \& Training Performance}

Training programs for new employees are expensive (e.g. the municipality used for this study spends over $\$ 10,000$ per month, per applicant). Accordingly, a great deal of money is lost if an organization provides training to individuals who later resign because they are uncomfortable with the job duties. If an organization could use a tool such as a personality test to disqualify those applicants that are unlikely to succeed, the organization could thus save the time and money spent on training new candidates who subsequently fail during either training or probationary periods (Inwald \& Shusman, 1984).

An employer trying to decide whether or not to use a personality inventory as a screening tool must use meta-analytic findings with care. Prior to use for selection purposes, an inventory must be validated for use with a particular type of job. Schneider and Schmitt (1986; as cited in Cortina et al., 1992) suggested that the typical failure of personality tests to improve personnel selection may be due to the fact that most personality tests have not been based on job analyses nor have they considered the occupation for which they were used. The Hogan Personality Inventory (HPI; Hogan \& Hogan, 1995) is a solution to this problem, for unlike many other personality inventories, it was developed to be used primarily for personnel selection purposes. For this reason, I chose to use the HPI for this study, the scales of which I will define in the Methods section.

Studies conducted using a firefighter population are limited (Hogan \& Stark, 1992). In these studies, research on the relationship between personality characteristics and firefighter training performance is lacking. Obtaining this information is important 
because if a municipality could reduce fire academy failures by use of a personality measure, not only could the effectiveness of the fire academy increase, but having the ability to reduce the number of academy failures would prove to be financially beneficial.

Based on this discussion, I hypothesize that the personality scales of Sociability (Extraversion), Prudence (Conscientiousness), Likeability (Agreeableness), and Intellectance (Openness to Experience) will predict overall training performance.

\section{The Role of Motivation on the Personality - Performance Link}

Few studies have looked at how one's motivation may complement his/her personality traits. In a study of 164 telemarketing sales representatives, Stewart, Barrick, \& Piotrowski (2000) investigated the mediating effects of motivation on personality in predicting job performance. The personality predictor was produced by use of the Occupational Personality Questionnaire (a measure of the five factor model of personality), and job performance was assessed by supervisor's ratings. The motivation predictor was produced by an inventory they developed (Motivational Orientation Inventory) which measured three types of motivation: Getting Along With Others, Getting Ahead, and Getting Things Done. The Getting Along With Others construct is similar to that of the Affiliation scale on the Motives, Values, Preferences Inventory (MVPI; Hogan \& Hogan, 1996), which measures the degree to which one may have a desire for and enjoyment of social interaction. The Getting Ahead Construct is similar to the Power scale on the MVPI, which is associated with a desire for success, accomplishment, status, competition, and control (Hogan \& Hogan, 1996). The Getting Things Done construct does not seem to have a good match on the MVPI; however, it too 
seems most similar to the Power scale. Their study found that a substantial portion of the extraversion-performance relationship was carried through the Getting Ahead construct and that a substantial portion of the conscientiousness-performance relationship was carried through the Getting Things Done construct. Additionally, they found that a major portion of the relationship between extraversion and performance was indirect through Getting Ahead of Others (indirect effect $=.15$, direct effect $=-.10$ ).

Borman and Motowidlo (1993) distinguish between technical and contextual performance, the former being actual job tasks while the latter encompasses organizational citizenship behaviors/ prosocial organizational behaviors, which are personality related. They point out that often is the case when technical performance and contextual performance are weighted about equally by supervisors when making overall performance ratings (Borman \& Motowidlo, 1993; Motowidlo \& Van Scotter, 1994). Similarly, McCloy, Campbell, and Cudeck (1994) concluded out that the motivational element of performance is linked to personality. Given the aforementioned research, my second hypothesis is that the Affiliation scale of the MVPI, which is a self-report measure of organizational citizenship behavior, will predict training performance. My third hypothesis is that the relationship between personality and high risk performance is moderated by one's motivation, as measured by the MVPI's Power motive, which is a measure of one's competitiveness and drive for success. 1 predict that this moderation will be higher for those who are low thrill seekers.

Some researchers (Hough \& Schneider, 1996; Stewart, 1999) have argued that narrower traits should be used when using personality to predict job performance, in an effort to increase the predictive power of personality scores. Others point out that 
broader traits are probably more reliable and practical, since job performance criteria are usually complex (Ones \& Viswesvaran, 1996). The HPI's 43 Homogeneous Item Composites (HICs), separated into 7 primary scales, allow for the investigation of the effects of both broad bandwidth (HPI primary scales) and high fidelity traits (HICs). Stewart (1999) investigated the impact that Costa and McCrae's (1992) "Order" and "Achievement" subtraits of the Revised NEO Personality Inventory (NEO PI-R) had on employee success during the "maintenance" and "transition" stages of job performance. Murphy (1989) describes the maintenance stage as the period when an employee "has learned to perform all major job tasks and is no longer confronted with situations that present novel or unpredictable demands" (p. 190), whereas the transition stage is described as occurring when "job duties, procedures, and methods of operation are new and undefined; the workers must learn new skills and tasks and make decisions about unfamiliar topics" (p. 190). He demonstrated that the NEO-PI's Conscientiousness scale did not predict as much of the variance as its subtrait of Order for employees in the transition phase of employment. The NEO PI-R "Order" subtrait describes the desire to structure and organize one's environment. Similarly, the HPI's "Not Spontaneous" subtrait is described as the preference for predictability; therefore, since the fire academy cadets are in this transition phase, it is predicted that those candidates that score high on the "Not Spontaneous" HIC will have higher training performance ratings, as measured by the Cadet Evaluation Form than those who score low on the "Not Spontaneous" HIC. In a study of police academy recruits, Inwald and Shusman (1984), found that more of the training performance variance was explained by using both the MMPI and IPI. However, Cortina et al. (1992), determined that there was little evidence to suggest 
that both of these batteries need to be used in order to maximize predictability with police recruits. Since the present study is not using two personality inventories, but rather a personality inventory and a motivation inventory, my fifth and final hypothesis is that more of the variance of fire academy performance will be explained by using the two inventories than either inventory by itself.

\section{Summary of Hypotheses}

The hypotheses for this study are as follows:

1. The personality scales of Sociability (Extraversion), Prudence (Conscientiousness), Likeability (Agreeableness), and Intellectance (Openness to Experience) will predict overall training performance.

2. That the Affiliation scale will predict overall training performance.

3. The relationship between personality and high risk performance is moderated by the Power motive. This moderation is higher for those who are low thrill seekers.

4. That those candidates that score high on the "Not Spontaneous" HIC will have higher training performance ratings than those who score low on the "Not Spontaneous" HIC.

5. That more of the variance of fire academy performance will be explained by using both the HPI and MVPI than would be if using either one of the inventories alone. 


\section{METHODS}

\section{Subjects and Design}

The sample consisted of 109 Firefighter Candidates from three academy classes.

The Academy is traditionally an eight month program; however, in the event that a candidate already had a firefighter certification, only four months of the academy was required. Each class contained a mix of male and female candidates. The end sample had 98 men and 11 women. Candidates ranged in age from 20 to 43, with a mean of 27 (Standard Deviation $=4.67)$. The ethnic backgrounds reported were American Indian $(n$ $=1)$, Black $(n=18)$, White $(n=19)$, Hispanic $(n=68)$, and Other $(n=2)$.

Candidates were in training on weekdays, from 8:00 am to $4: 00 \mathrm{pm}$. The academy followed the curriculum of the Florida State Fire College 360-Hour Minimum Standards Outline, which included lectures on First Aid, Fire Behavior, Portable Extinguishers, Protective Breathing Apparatus, Ropes and Knots, Rescue and Extraction, Forcible Entry, Ventilation, Ladders, Water Supply, Fire Streams, Fundamentals of Extinguishment, Automatic Sprinkler Systems, Salvage and Overhaul, Building Construction, Fire Cause Determination, Fire Alarms and Communications, Fire Prevention and Public Education, Firefighter Safety, Hazardous Materials, and Live Burning. 


\section{Criteria}

Training performance was determined by two overall performance measures on the Cadet Evaluation Form (see Appendix A). The Cadet Evaluation provides an overall assessment of the candidates' performance as assessed by the trainers.

High Risk Activity performance was measured by a composite score of the three high-risk activities in which each candidate participated: the Live Burn, which is an exercise in which candidates enter a burning structure; the Air Bag, which involved jumping off the roof of a six (6) story building into a large air bag; and Rope Rescue, which involved rappelling down the side of a building and extracting and lowering a victim to the ground floor.

\section{Predictors}

Personality and motivation factors were measured by the Hogan Personality Inventory (HPI); and Motives, Values, Preferences Inventory (MVPI), respectively. The HPI is divided into seven (7) scales: Adjustment, Ambition, Sociability, Likeability, Prudence, Intellectance, and School Success. Adjustment (Alpha $=.89$ ) measures the degree to which a person appears calm and self-accepting, or conversely, self-critical and tense; Ambition (Alpha $=.86$ ) measures the degree to which a person seems socially selfconfident, leader-like, competitive, and energetic; Sociability (Alpha $=.83)$ measures the degree to which a person seems to need and/or enjoy interacting with others; Likeability $($ Alpha $=.71)$ measures the degree to which a person is seen as perceptive, tactful, and socially sensitive; Prudence (Alpha $=.78$ ) measures the degree to which a person seems conscientious, conforming, and dependable; Intellectance (Alpha $=.78)$ measures the 
degree to which a person is perceived as bright, creative, and interested in intellectual matters; and School Success (Alpha $=.75$ ) measures the degree to which a person seems to enjoy academic activities and to value educational achievement for its own sake.

The MVPI is divided into 12 scales: Aesthetic Motives, Affiliation Motives, Altruistic Motives, Commercial Motives, Hedonistic Motives, Power Motives, Recognition Motives, Scientific Motives, Security Motives and Tradition Motives. Aesthetic Motives $($ Alpha $=.84)$ are associated with an interest in art, literature, music, the humanities, and a lifestyle guided by questions of culture, good taste, and attractive surroundings. Affiliation motives $($ Alpha $=.71)$ are associated with a desire for and enjoyment of social interaction. Altruistic motives $($ Alpha $=.81)$ involve concern about the welfare of others, especially the less fortunate, a desire to help them, and in some way, contribute to the development of a better society. Commercial motives (Alpha $=$ .71) reflect an interest in business and business-related matters such as accounting, marketing, management, and finances. Hedonistic motives (Alpha $=.78)$ produce an orientation toward fun, pleasure, and enjoyment. Power motives $($ Alpha $=.71)$ are associated with a desire for success, accomplishment, status, competition, and control. Recognition motives $($ Alpha $=.77)$ reflect responsiveness to attention, approval, praise, a need to be recognized, and an appreciation for the role of recognition in human motivation. Scientific motives (Alpha $=.80$ ) are associated with a desire for knowledge, and enthusiasm for new and advanced technologies, and a curiosity about how things work. Security motives (Alpha $=.70)$ reflect a desire for certainty, predictability, order, and control in one's life. Finally, Tradition motives (Alpha $=.80)$ are typically expressed in terms of a dedication to ritual, history, spirituality, and old-fashioned virtues. 


\section{Procedure}

The City of Miami's Fire Department conducted a series of training academy classes, each containing both already certified firefighters and non-certified candidates. In the first week of training, the cadets completed the HPI and MVPI. The certified group were in the academy for four months, the non-certified for eight months. At the time of each group's graduation, the academy's trainers completed Cadet Evaluation Forms for each candidate, which provided two ratings of overall performance.

Correlation Coefficients were used to determine the relationship between personality or motivation inventory scales and training performance for Hypotheses one (1), two (2) and four (4); and Multiple Regression was used to determine whether or not a moderation existed for hypothesis three (3) and the extent of incremental variance in hypothesis five (5). 
Table 1 summarizes the demographic characteristics of the sample. Although skewed in terms of gender (more males than females) and race (more Hispanics), this composition is reflective of the characteristics of the City of Miami firefighter population.

TABLE 1

\begin{tabular}{|l|c|c|}
\hline Race & $\begin{array}{c}\text { Males } \\
\text { (Mean age) (SD) }\end{array}$ & $\begin{array}{c}\text { Females } \\
\text { (Mean age) (SD) }\end{array}$ \\
\hline $\begin{array}{l}\text { American } \\
\text { Indian }\end{array}$ & $\begin{array}{c}(27) \\
\text { Black }\end{array}$ & - \\
\hline White & $\begin{array}{c}18 \\
(27.67)(3.79)\end{array}$ & - \\
\hline Hispanic & 14 & 5 \\
& $(27.14)(5.17)$ & $(31.40)(6.88)$ \\
\hline Other & 63 & $5^{*}$ \\
& $(26.48)(4.59)$ & $(24.25)(3.86)$ \\
\hline TOTAL & - & 1 \\
& 96 & $(22)$ \\
\hline & $(26.78)(4.48)$ & $\begin{array}{c}11 \\
(27.6)(6.52)\end{array}$ \\
\hline & & $\begin{array}{c}\text { *One subject did } \\
\text { not report her } \\
\text { age. }\end{array}$ \\
\hline
\end{tabular}

Table 2 provides the intercorrelations among the seven primary scales of the HPI. The lowest correlation was between Prudence and Intellectance (.02) and the highest was between Prudence and Adjustment (.62), with an average correlation of .21. These findings are in line with those reported in the HPI Manual, where the highest correlation, 
also between Prudence and Adjustment, was .58; and the lowest correlation, also between Prudence and lntellectance, was .00, with an average correlation of .24.

TABLE 2

\begin{tabular}{|c|c|c|c|c|c|c|c|}
\hline HPI Scales: & Adj & Amb & Int & Lik & Pru & Sch & Soc \\
\hline Adjustment & $(.89)^{*}$ & & & & & & \\
\hline Ambition & .46 & $\begin{array}{c}(.86) \\
*\end{array}$ & & & & & \\
\hline Intellectance & .07 & .32 & $\begin{array}{c}(.78) \\
*\end{array}$ & & & & \\
\hline Likeability & .46 & .25 & .04 & $(.71)^{*}$ & & & \\
\hline Prudence & .62 & .31 & .02 & .42 & $(.78)^{*}$ & & \\
\hline $\begin{array}{l}\text { School } \\
\text { Success }\end{array}$ & .34 & .37 & .37 & .15 & .09 & $\begin{array}{c}(.75) \\
* \\
\end{array}$ & \\
\hline Sociability & -.27 & .19 & .41 & -.08 & -.37 & .15 & $\begin{array}{c}(.83) \\
*\end{array}$ \\
\hline
\end{tabular}

*Alpha reliabilities shown come from HPI Manual

Table 3 provides the intercorrelations among the ten scales of the MVPI. The lowest correlation was between Tradition Motives and Recognition Motives (.00) and the highest was between Recognition Motives and Hedonistic Motives (.57), with an average correlation of .19. These findings are similar to those reported in the MVPI Manual, where the correlation between Tradition Motives and Recognition Motives (-.06) is the fourth lowest correlation of the 45 intercorrelations, and the correlation between Recognition Motives and Hedonistic Motives (.43) is the third highest correlation of the 45 inter-correlations, with an average correlation of .16. 
TABLE 3

\begin{tabular}{|c|c|c|c|c|c|c|c|c|c|c|}
\hline $\begin{array}{l}\text { MVPI } \\
\text { Scales: }\end{array}$ & Aes & Aff. & Alt. & Com. & Hed. & Pow. & Rec. & Sci. & Sec. & Tra. \\
\hline Aesthetic & $(.84)^{*}$ & & & & & & & & & \\
\hline Affiliation & -.12 & $(.71)^{*}$ & & & & & & & & \\
\hline Altruistic & .22 & .32 & $\begin{array}{c}(.81) \\
*\end{array}$ & & & & & & & \\
\hline Commercial & .27 & .09 & .19 & $(.71)^{*}$ & & & & & & \\
\hline Hedonistic & .26 & 36 & .04 & .22 & $(.78)^{*}$ & & & & & \\
\hline Power & .20 & .23 & .24 & .33 & .40 & $\begin{array}{c}(.71) \\
*\end{array}$ & & & & \\
\hline Recognition & .30 & .35 & .14 & .33 & .57 & .39 & $\begin{array}{c}(.77) \\
*\end{array}$ & & & \\
\hline Scientific & .41 & .03 & .25 & .26 & .21 & .21 & .35 & $\begin{array}{c}(.80) \\
* \\
\end{array}$ & & \\
\hline Security & -.06 & -.04 & .29 & .18 & -.15 & .08 & .03 & .05 & $\begin{array}{c}(.70) \\
*\end{array}$ & \\
\hline Traditional & .24 & -.08 & .32 & .17 & -.12 & .20 & .00 & .08 & .34 & $\begin{array}{c}(.80) \\
*\end{array}$ \\
\hline
\end{tabular}

*Alpha reliabilities shown come from MVPI Manual

Table 4 provides the intercorrelations among seven criterion measures. Overall

Performance Measures \#1 and \#2 were derived by averaging the trainers' ratings given for a particular employee for the respective performance measures.

TABLE 4

\begin{tabular}{|l|c|c|c|c|c|c|}
\hline HPI Scales: & OP1 & OP2 & OPZ & HR1 & HR2 & HR3 \\
\hline Overall Perf. \#1 & - & & & & & \\
\hline Overall Perf. \#2 & .91 & & & & & \\
\hline Overall Perf. Z & -.54 & -.50 & & & & \\
\hline High Risk \#1 & .45 & .41 & .05 & & & \\
\hline High Risk \#2 & .15 & .12 & .09 & .54 & & \\
\hline High Risk \#3 & .40 & .43 & .00 & .73 & .57 & \\
\hline $\begin{array}{l}\text { Overall High } \\
\text { Risk }\end{array}$ & .41 & .40 & .04 & .91 & .75 & .91 \\
\hline
\end{tabular}


Since the two overall performance measures were rated on different scales, the scores were standardized and averaged to create one overall performance measure, Overall Performance $Z$ which is simply the z-score of the combined performance measures. High Risk \#1, \#2, and \#3 were the airbag, rope rescue and live-burn exercises respectively. Finally, the Overall High Risk measure was simply a sum of the high risk measures.

The lowest correlation was between High Risk Performance Measure \#3 (live burn) and the Z-score of Overall Performance (.00). The correlations between Overall High Risk Performance and High Risk Performance Measure \#1 (airbag); Overall High Risk Performance and High Risk Measure \#3 (live burn); and Overall High Risk Performance and Overall Performance Measure \#1 were all .91.

The correlations between the seven HPI scales and the performance criteria are presented in Table 5, and the correlations between the $10 \mathrm{MVPl}$ scales and the performance criteria are presented in Table 6.

TABLE 5

\begin{tabular}{|l|c|c|c|}
\hline HPI Scales: & $\begin{array}{c}\text { Academic } \\
\text { Performance }\end{array}$ & $\begin{array}{c}\text { Overall } \\
\text { Performance }\end{array}$ & $\begin{array}{c}\text { High Risk } \\
\text { Performance }\end{array}$ \\
\hline Adjustment & -.18 & -.06 & -.04 \\
\hline Ambition & -.12 & -.04 & -.01 \\
\hline Intellectance & -.08 & .03 & .05 \\
\hline Likeability & -.10 & -.03 & -.08 \\
\hline Prudence & -.18 & -.09 & -.01 \\
\hline $\begin{array}{l}\text { School } \\
\text { Success }\end{array}$ & .02 & .11 & -.08 \\
\hline Sociability & .09 & .13 & .09 \\
\hline $\begin{array}{l}\text { Academic } \\
\text { Perf. }\end{array}$ & - & -.04 & .07 \\
\hline
\end{tabular}


The first hypothesis predicted that the HPI scales of Sociability, Prudence,

Likeability, and Intellectance would predict overall training performance. The hypothesis was partially supported, because the personality scale with the highest correlation to overall performance was Sociability $(.13)$. This finding is reasonable because the training academy is a very social environment, therefore, candidates that are more introverted would likely be outcast. The next most predictive scale was the School Success scale (.11), which was not hypothesized, but could be explained by the fact that a large part of the impression that instructors had of the candidates may have been based upon the scores the candidates received on the academic tests that followed each section of the academy. At the .05 level, none of the correlations were significant (Table 5).

TABLE 6

\begin{tabular}{|l|c|c|c|c|}
\hline MVPI Scales: & $\begin{array}{c}\text { Thrillseeker } \\
\text { HIC }\end{array}$ & $\begin{array}{c}\text { Not- } \\
\text { Spontaneous } \\
\text { HIC }\end{array}$ & $\begin{array}{c}\text { High-Risk } \\
\text { Perf. (r) }\end{array}$ & $\begin{array}{c}\text { Overall } \\
\text { Perf. (r) }\end{array}$ \\
\hline Aesthetic & .31 & -.23 & -.03 & .22 \\
\hline Affiliation & .24 & -.12 & -.08 & -.16 \\
\hline Altruistic & .12 & .12 & -.32 & -.11 \\
\hline Commercial & .07 & -.03 & .14 & .06 \\
\hline Hedonistic & .23 & -.38 & -.04 & -.01 \\
\hline Power & .25 & .05 & -.09 & -.16 \\
\hline Recognition & .28 & -.23 & -.01 & -.11 \\
\hline Scientific & .31 & -.12 & -.03 & -.03 \\
\hline Security & -.26 & .33 & -.13 & -.11 \\
\hline Traditional & .0000 & .07 & -.15 & -.02 \\
\hline Thrill-Seeker HIC & - & -.19 & .21 & -.04 \\
\hline $\begin{array}{l}\text { Not Spontaneous } \\
\text { HIC }\end{array}$ & -.19 & - & .14 & .04 \\
\hline
\end{tabular}

The second hypothesis, which predicted that the MVPI's Affiliation scale would predict overall training performance, went unsupported with a correlation coefficient of $.16(\mathrm{p} \leq .106)$. 
The third hypothesis posited that if one has a lower thrill-seeking personality (as determined by the HPI's Thrillseeker HIC), yet he/she is highly motivated (as determined by the MVPI's Power Motives), that he/she will still perform well on the high risk activities, as measured by an overall high-risk performance score. This overall high-risk performance score was derived by combining the Airbag, Live-burn, and Rope Rescue scores $($ Alpha $=.81)$ into an overall high-risk performance score.

In other words, it was predicted that the degree to which one's motivation moderates the high-risk performance score will be greater for those candidates that are low thrill-seekers than for those candidates that are high thrill-seekers. For the sample of low thrill-seeker subjects, the $r^{2}$ for the motivation and thrill-seeking variables was $.0578(\mathrm{~F}=.7665)$. Adding the combined variable (thrill-seeking $\mathrm{x}$ motivation) into the equation provided a $\Delta \mathrm{r}^{2}$ of $.0217(\Delta \mathrm{F}=.5652)$. On the other hand, for the sample of high thrill-seeker subjects, the $\mathrm{r}^{2}$ for the motivation and thrill-seeking variables was $.0513(\mathrm{~F}=$ 1.6226). Adding the product variable (thrill-seeking $x$ motivation) into the equation provided a $\Delta \mathrm{r}^{2}$ of $.0004(\Delta \mathrm{F}=.0215)$. Although motivation seems to moderate personality when predicting training performance to a greater extent in the low thrillseeker sample than it does in the high thrill-seeker sample, the results are not significant, and therefore the fifth hypothesis goes unsupported. The results are summarized in Table 7.

Hypothesis four was also not supported. The correlation coefficient between the "Not Spontaneous" HIC and overall performance was -.04 ( $\mathrm{p} \leq .700)$, and therefore not statistically significant. 
TABLE 7

\begin{tabular}{|c|c|c|}
\hline $\begin{array}{c}\text { Total Thrill-Seeker } \\
\text { Sample }(N=109)\end{array}$ & Beta & Beta \\
\hline Thrill-Seeking HIC & .25 & .66 \\
\hline Power Motive (MVPI) & -.16 & -.03 \\
\hline $\begin{array}{c}\text { Thrill-Seeking x Power } \\
\text { Motive }\end{array}$ & - & -.46 \\
\hline $\mathrm{r}^{2}$ & .07 & .07 \\
\hline$\Delta \mathrm{r}^{2}$ & - & .00 \\
\hline $\mathrm{F}\left(\mathrm{df}_{1}, \mathrm{df}_{2}\right)$ & $3.17(2,88)$ & $2.15(3,87)$ \\
\hline
\end{tabular}

The only HICs that did show statistical significance at the .05 level were "No Somatic Complaints" $(r=-.27, p \leq .005)$, "Impression Management" $(r=.20, p \leq .036)$, "No Depression" ( $r=-.19, \mathrm{p} \leq .046)$, and "No Social Anxiety" $(\mathrm{r}=.17, \mathrm{p} \leq .080)$. High scores on the "No Somatic Complaints", "No Depression", and "No Social Anxiety" HICs describe individuals with a positive outlook and social confidence, and in an environment that involves a great deal of teamwork, it makes sense that positive people would do better. Similarly, Impression Management refers to the degree to which an individual is a self-monitor, so it makes sense that the ability to align with the status quo in a team environment would also lead to higher performance scores.

The final hypothesis simply predicted that more of the variance in performance would be explained with both inventories rather than either one. The change in $r^{2}$ when HPI scales were added to the MVPI scales was .0569 , whereas the change in $r^{2}$ when the MVPI scales were added to the HPI scales was .1613. Both $\Delta \mathrm{r}^{2} \mathrm{~s}$ were significant, thus supporting the fifth hypothesis. The results are summarized in Table 8. 
TABLE 8

\begin{tabular}{|l|c|c|c|c|}
\hline MVPI Scales: & Regression & Regression & Regression & Regression \\
& 1 & 2 & 3 & 4 \\
\hline Adjustment & -.02 & -.02 & - & -.02 \\
\hline Ambition & -.09 & -.05 & - & -.05 \\
\hline Intellectance & -.05 & -.09 & - & -.09 \\
\hline Likeability & .00 & .08 & - & .08 \\
\hline Prudence & -.01 & -.01 & - & -.01 \\
\hline School Success & .15 & .19 & - & .19 \\
\hline Sociability & .13 & .24 & - & .24 \\
\hline Aesthetic & - & .30 & .29 & .30 \\
\hline Affiliation & - & -.07 & -.03 & -.07 \\
\hline Altruistic & - & -.15 & -.08 & -.15 \\
\hline Commercial & - & .06 & .14 & .06 \\
\hline Hedonistic & - & -.01 & .05 & -.01 \\
\hline Power & - & -.14 & -.18 & -.14 \\
\hline Recognition & - & -.21 & -.15 & -.21 \\
\hline Scientific & - & -.07 & -.09 & -.07 \\
\hline Security & - & -.04 & -.08 & -.04 \\
\hline Traditional & - & .00 & -.01 & .00 \\
\hline \multicolumn{1}{|c|}{$\mathrm{r}^{2}$} & .0376 & .20 & .14 & .20 \\
\hline$\Delta \mathrm{r}^{2}$ & & -.16 & & -.06 \\
\hline $\mathrm{F}\left(\mathrm{df}_{1}, \mathrm{df}_{2}\right)$ & $.5639(7,101)$ & $1.33(17,91)$ & $1.62(10,98)$ & $1.33(17,91)$ \\
\hline
\end{tabular}




\section{DISCUSSION}

It is important to note that one limitation of a study done in this manner is that it suffers from restriction of range. In order to be admitted into the training academy, the candidates first had to have applied for the job. Those applicants determined to be qualified had to then successfully complete a cognitive ability test, and were then eligible for the training academy. In the case of this sample, there were originally 631 applicants, 29 of which were deemed ineligible, another 150 failed the cognitive ability test, and 81 did not appear. Of the 371 that passed, 109 were chosen randomly to go through the training academy. Point being that the possibility exists that there may be less variability in personality scores of this sample than in that of the general population. Those who did not pass the cognitive test screening never had their performance evaluated.

For this study, none of the HPI scales was able to predict training performance with any significance. The scales that had the highest correlation with overall training performance were Sociability $(r=.1268, p=.189)$ and School Success $(r=.1083, p=$ .262). On the other hand, three of the MVPI scales were able to predict with significance: Aesthetic motives $(r=.2158, p=.024)$, Power Motives $(r=-.1625, p=$ $.091)$, and Affiliation motives $(r=-.1555, \mathrm{p}=.106)$.

Motivation seems to better predict academy performance than does personality in this study, which could be due to the fact that the future employment of these candidates depended upon their performance at the academy. It can be presumed that in such a setting, participants will put forth the required effort to ensure future paychecks. However, the purpose of the study was not to determine what applications would be the best use for these inventories, but rather whether or not the inventories could be used in 
this application to predict training performance. Since the HPI has been validated with other personality tests, peer ratings and measures of Organizational Behavior; and the MVPI has been validated with other measures of interests and peer ratings, it stands to reason that the weak point of this study was the criterion measures, not the predictors.

Rather than using only two overall performance measures, Borman (1991) suggests that multiple criteria are more appropriate when trying to determine the relationships between predictors and criterion. Further studies should include performance measures that are designed to align with the goals of the training academy, which should stem from the essential functions of the job as determined by a job analysis. Unfortunately, the design of the academy is often beyond the influence of the researcher. Through discussions with many of the trainers at this academy, it seems that much of the emphasis was on physical fitness, yet none of the performance measures was a measure of physical fitness. It is very possible that since no clear-cut goals were established at the start of the academy, in rating overall performance the trainers didn't really have a good grasp as to what they were rating.

Another important point is that recent research has claimed that bidirectionality exists in the personality- job performance relationship. According to Tett, Jackson, and Rothstein (1999), a particular trait may have a positive relationship to performance in one job, while at the same time have a negative relationship to performance in another job. Hence, caution is needed in generalizing these differences beyond the firefighting population.

It should be pointed out that even though some of the motivation scales were able to predict performance with significance, at this time there is no research that suggests 
that these motives have any correlation at all with actual Firefighter job performance.

Granted, as per Washington vs. Davis (1976), which dealt specifically with the firefighter population, training performance can be used as a selection criteria, given that the training program is correlated to the job performance, but that has not yet been established for the Fire Department used in this study. As noted by Spielberger (1979), intelligence and ability tests were less reliable in predicting job performance than they were in predicting academy performance. Further research should investigate whether these personality measures do, in fact, have a similar relationship with actual firefighter job performance. Although using personality tests as screening tools is appealing, they must be used with caution. Prior to use in any arena, a test must be validated for that specific purpose in order to avoid damaging litigation (Topp \& Kardash, 1986). 


\section{LIST OF REFERENCES}

Anderson, G., \& Viswesvaran, C. (1998, ). An Update of the Validity of Personality Scales in Personnel Selection: A Meta-Analysis of Studies Published After 1992. Paper presented at the Society for Industrial and Organizational Psychology, Dallas, TX.

Azen, S. P., Snibbe, H. M., \& Montgomery, H. R. (1973). A longitudinal predictive study of success and performance of law enforcement officers. Journal of Applied Psychology, 57, 190-192.

Baehr, M. E., Furcon, J. E., \& Froemel, E. C. (1968). Psychological assessment of patrolman qualification in relation to field performance. Washington: U.S. Government Printing Office.

Barrick, M. R., \& Mount, M. K. (1991). The Big Five personality dimensions and job performance: A meta-analysis. Personnel Psychology, 44(1), 1-26.

Bartol, C. R. (1991). Predictive validation of the MMPI for small-town police officers who fail. Professional psychology: Research and practice, 22, 127-132.

Bonsignore v. City of New York, 683 F.2d 635 (N.Y 1981).

Borman, W. (1991). Job Behavior, Performance, and Effectiveness. In M.D. Dunnette \& L.M. Hough (Eds.), Handbook of Industrial \& Organizational Psychology (pp. 272-326). Palo Alto: Consulting Psychologists Press, Inc.

Borman, W., \& Motowidlo, S. J. (1993). Expanding the criterion domain to include elements of contextual performance. In N. Schmitt \& W. C. Borman (Eds.), Personnel selection in organizations (pp. 71-98). San Francisco: Jossey-Bass.

Burbeck, E., \& Furnham, A. (1985). Police Officer Selection: A Critical Review of the Literature. Journal of Police Science and Administration, 13, 58-69.

Butcher, J. N. (1979). Use of the MMPI in personnel selection. In J. N. Butcher (Ed.), New developments in the use of the MMPI . Minneapolis, MN: University of Minnesota Press.

Campbell, J.P. (1991). Modeling the performance prediction problem in industrial and organizational psychology. ln M.D. Dunnette \& L.M. Hough (Eds.) Handbook of industrial and organizational psychology. Chicago: Rand McNally.

Conte v. Horcher, June 16 (Appellate Court of Illinois 1977). 
Cortina, J. M., Doherty, M. L., Schmitt, N., \& Kaufman, G. (1992). The "Big Five" personality factors in the IPI and MMPI: Predictors of police performance. Personnel Psychology, 45, 119-140.

Costa, P.T. \& McCrae, R.R. (1985). The NEO-PI Personality Inventory. Odessa, FL: Psychological Assessment Resources.

Costa, P.T., \& McCrae, R.R. (1992). Revised NEW personality inventory (NEO PI-R) and NEW five-factor Inventory (NEO FFI) professional manual. Odessa, FL: Psychological Assessment Resources, Inc.

Eisenberg, T., \& Dowdle, M.D. (1981). Officer selection and performance study, San Jose Police Department. San Jose, CA: Office of Criminal Justice Planning.

Gottlieb, M. C., \& Baker, C. F. (1974). Predicting police officer effectiveness. Joumal of Forensic Psychology(December), 31-46.

Hargrave, G., \& Berner, J. (1984). Post psychological screening manual. Sacramento, CA: Commission on Peace Officer Standards.

Hargrave, G. E. (1985). Using the MMPI to screen law enforcement applicants: A study of reliability and validity of clinicians' decisions. Journal of Political Science and Administration, 13, 221-224.

Hiatt, D., \& Hargrave, G. E. (1988). Predicting job performance problems with psychological screening. Journal of Police Science \& Administration, 16(2), 122-135.

Hogan R., \& Hogan, J. (1995). Hogan Personality Inventory Manual. Tulsa, OK: Hogan Assessment Systems.

Hogan, J., \& Hogan, R. (1996). Motives, Values, Preferences Inventory Manual. Tulsa, OK: Hogan Assessment Systems.

Hogan, J., \& Stark, D. (1992). Using Personality Measures to Select Firefighters. Paper presented at the International Personnel Management Association Assessment Council, Baltimore, MD.

Hogan, R., Hogan, J., \& Roberts, B. W. (1996). Personality measurement and employment decisions. American Psychologist, 51, 469-477.

Hogan, R., \& Kurtines, W. (1975). Personological correlates of police effectiveness. Joumal of Psychology, 91, 289-291.

Hough, L. M., \& Schneider, R. J. (1996). Personality traits, taxonomies, and applications in organizations. In K. R. Murphy (Ed.), Individual differences and behavior in organizations. San Francisco: Jossey-Bass. 
Inwald, R. E., \& Shusman, E. J. (1984). The IPI and MMPI as predictors of academy performance for police recruits. Journal of Police Science \& Administration, 12(1), 1-11.

Lawrence, R. (1984). Police stress and personality factors: A conceptual model. Journal of Criminal Justice, 12, 247-263.

Leitner, D. W., \& Sedlacek, W. E. (1976). Characteristics of successful campus police officers. Journal of College Student Personnel(July), 304-308.

Marsh, S. H. (1962). Validating the selection of deputy sheriffs. Public Personnel Review, 23, 41-44.

McCloy, R. A., Campbell, J. P., \& Cudeck, R. (1994). A confirmatory test of a model of performance determinants. Journal of Applied Psychology, 79, 493-505.

McKenna v. Fargo, May 25 (United States District Courts, New Jersey 1978).

Motowidlo, S. J., \& Van Scotter, J. R. (1994). Evidence that task performance should be distinguished from contextual performance. Journal of Applied Psychology, 79, 475-480.

Mount, M. K., Barrick, M. R., \& Stewart, G. L. (1998). Five-Factor Model of Personality and Performance in Jobs Involving Interpersonal Interactions. Human Performance, 11, 145-165.

Murphy, K. R. (1989). Is the relationship between cognitive ability and job performance stable over time? Human Performance, 2, 183-200.

Ones, D. S., \& Viswesvaran, C. (1996). Bandwidth-fidelity dilemma in personality measurement for personnel selection. Journal of Organizational Behavior, 17, 609-626.

Reilly, R. R., \& Warech, M. A. (1993). The validity and faimess of alternatives to cognitive tests. In L. C. Wing \& B. R. Gifford (Eds.), Policy issues in employment testing (pp. 131-224). Norwell, MA: Kluwer Academic.

Reiser, M., \& Geiger, S. (1984). Police Officer as victim. Professional psychology research and practice, 15, 315-323.

Roe, A. V., \& Roe, N. (1982). Police selection: A technical summary of validity studies. Orem, UT: Diagnostic Specialists.

Salgado, J.F. (1997). The five factor model of personality and job performance in the European community. Journal of Applied Psychology, 82, 30-43. 
Saxe, S. J., \& Reiser, M. (1976). A comparison of three police applicant groups using the MMPI. Journal of Police Science and Administration, 4, 419-425. Foresman.

Schneider, B., \& Schmitt, N. (1986). Staffing organizations. Glenview, IL: Scott,

Shusman, E. J., Inwald, R. E., \& Knatz, H. F. (1987). A cross-validation study of police recruit performance as predicted by the IPI and MMPI. Journal of Police Science \& Administration, 15(2), 162-169.

Society for Industrial and Organizational Psychology, Inc (1987). Principles for the validation and use of personnel selection procedures (Third Edition). College Park, MD: Author.

Spielberger, C. D. (1979). Police selection and evaluation: Issues and techniques. New York: Praeger Publishers.

Stewart, G. L. (1999). Trait bandwidth and stages of job performance: Assessing differential effects for conscientiousness and its subtraits. Paper presented at the 14th Annual Conference of the Society for Industrial and Organizational Psychology, Inc., Atlanta, GA.

Stewart, G. L., Barrick, M.R., \& Piotrowski, M. (2000). Personality and Sales Performance: Test of the Mediating Effects of Motivation. Paper presented at the 15 th Annual Conference of the Society for Industrial and Organizational Psychology, Inc., New Orleans, LA.

Tett, R. P., Jackson, D. N., \& Rothstein, M. (1991). Personality measures as predictors of job performance: A meta-analytic review. Personnel Psychology, 44, 703 742.

Tett, R. P., Jackson, D. N., \& Rothstein, M. (1999, ). Bidirectionality in personality-job performance relations. Paper presented at the 14th Annual Conference of the Society for Industrial and Organizational Psychology, Atlanta, GA.

Topp, B. W., \& Kardash, C. A. (1986). Personality, achievement, and attrition: Validation in a multiple-jurisdiction police academy. Joumal of Police Science and Administration, 14, 234-241.

Washington v. Davis, 96 S. Ct. 2040 (1976). 


\section{APPENDIX}

\section{City of Miami Department of Fire-Rescue \\ Performance Rating Form}

Your Name:

Name of the Candidate you are rating:
Date:

Class Number:

\section{Section 1: Behavior Ratings}

Circle the number that best represents your opinion.

Based on your observations during training, please rate the frequency that the candidate:

1. Perseveres with considerable effort over long periods of time

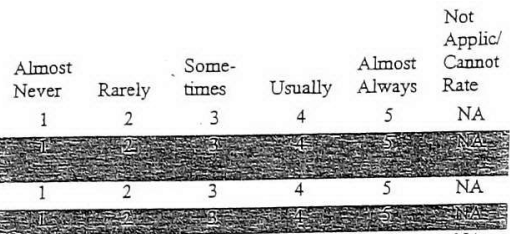

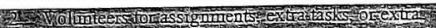

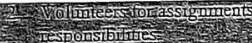

3. Pitches in to help or assist other candidates

4 स

5. Carries out training assignments efficiently $2-\frac{1}{3}$

6.

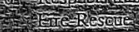

7. Expresses emotions in a mature way; doesn't lose temper

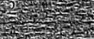

34

$4-5$

NA

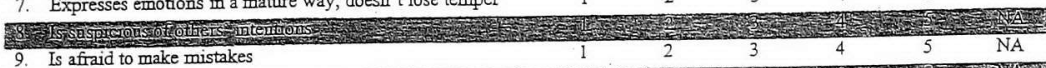

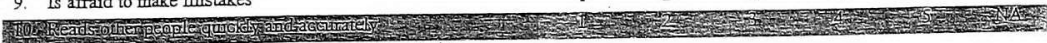

11. Becomes intated when asked to do something he/she doesn't want to do

(1)

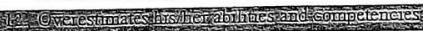

13. Resists close supervision and test the limits 14.

15. Acts in unexpected or peculiar ways

त्र

17. Is unwilling to act independently; needs frequent reassurance

1

2

$34 \quad 4 \quad 5 A$

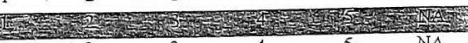

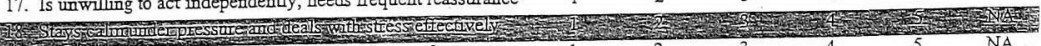

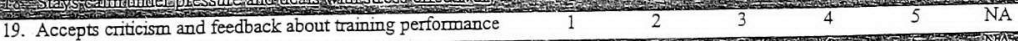

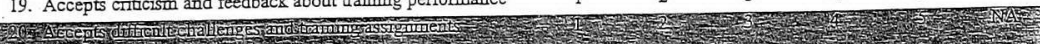

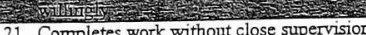

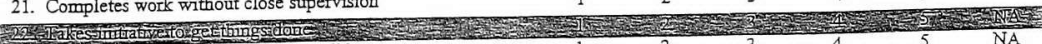

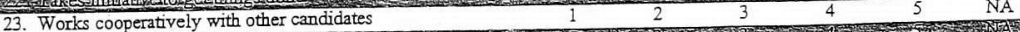

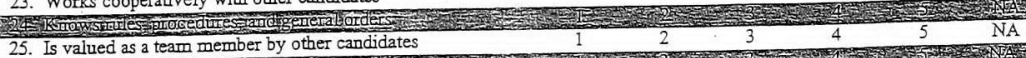

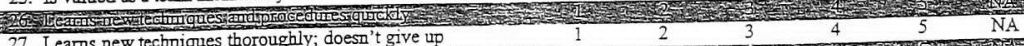
27. Ieams new techniques thoroughly; doesn't give up

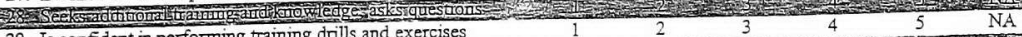

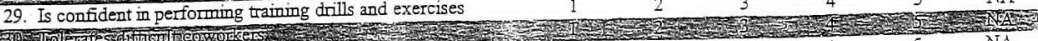
T0\% 31. Is open to new procedures and methods

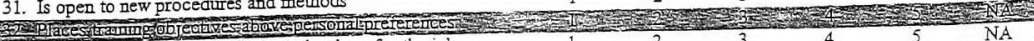

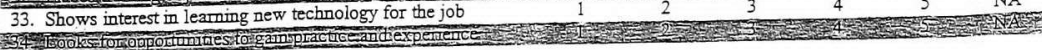




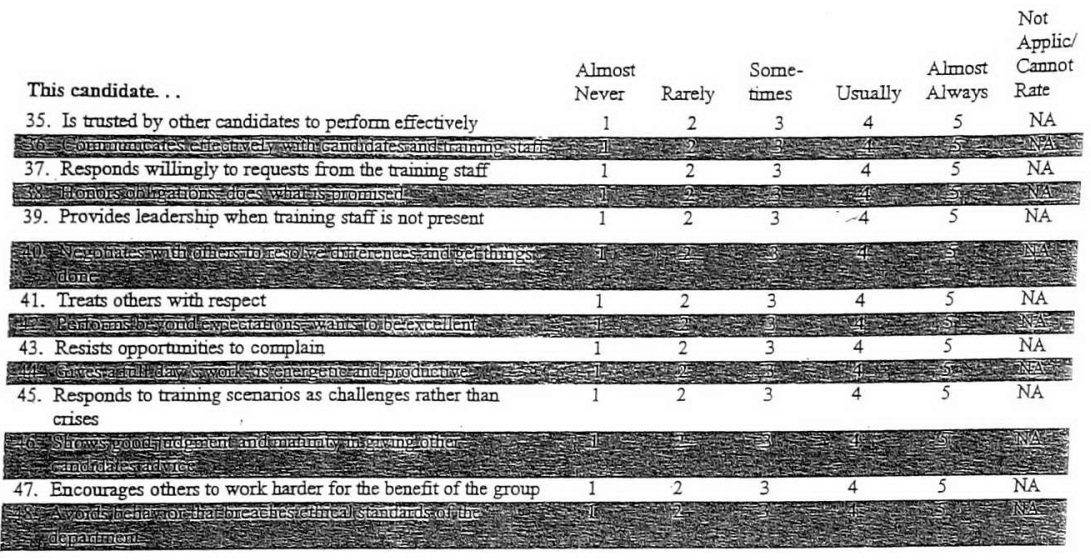

\section{Section 2: Overall Performance Ratings}

1. Please consider all the information you have provided in the previous section and past performance and make an overall rating of this candidate's performance during the training period. This rating is particularly important. Please think carefully before making your response. Circle the number that best represents your opinion.

$$
\begin{aligned}
& 1=\text { Far Below Expectations } \\
& 2=\text { Below Expectations } \\
& 3=\text { Slightly Below Expectations } \\
& 4=\text { Meets Expectations } \\
& 5=\text { Slightly Meets Expectations } \\
& 6=\text { Exceeds Expectations } \\
& 7=\text { Greatly Exceeds Expectations }
\end{aligned}
$$

2. Please evahuate this candidate in terms of his/her overall performance and contribution in the training class. Please circle the number that best represents your opinion.

$$
\begin{array}{ccc}
\text { Lower } 33 \% & \text { Middle } 33 \% & \text { Upper } 33 \% \\
1 & 2 & 3
\end{array}
$$

